\title{
Effect of environmental pollutants on the chemiluminescence of hemocytes from the American oyster Crassostrea virginica
}

\author{
K. G. Larson, B. S. Roberson, F. M. Hetrick \\ Department of Microbiology, University of Maryland, College Park, Maryland 20742, USA
}

\begin{abstract}
An assay measuring the chemiluminescent response of hemocytes from the oyster Crassostea virginica was used to assess the effects of environmental pollutants on phagocytosis. In vivo and in vitro effects of heavy metals (copper, cadmium, zinc, and aluminum), pesticides (dieldrin and chlordane), and organic compounds (naphthalene and 2,4-dinitrophenol) on the chemiluminescent response of stimulated oyster hemocytes were tested. In most cases, exposure to a high pollutant concentration reslilted in a decreased chemiluminescent response. After in vivo treatment, the response of the hemocytes depended on the duration of exposure to the pollutant and pollutant concentration. Instances of both acclimation and cumulative toxicity of pollutants were observed.
\end{abstract}

\section{INTRODUCTION}

Chemiluminescence (CL) is a measurable characteristic of stimulated macrophages and polymorphonuclear leukocytes (PMN). The CL assay was first described by Allen et al. (1972), using human PMN, and has been used to study phagocytosis in many species, including mice (Brummer et al. 1985), channel catfish (Scott \& Klesius 1981), striped bass (Stave et al. 1983), and rainbow trout (Elsasser et al. 1986).

Oyster hemolymph contains large numbers of phagocytes which are important in defense against infection (Cheng 1975, Ellis et al. 1975). Similar to other bivalve filter-feeding molluscs, oysters are likely to accumulate a variety of chemicals from the environment including copper (Pesch et al. 1979, Zamuda et al. 1983), cadmium (Zaroogian 1980), and pesticides such as dieldrin (Mason \& Rowe 1976, Emanuelson et al. 1978). This concentration thereby exposes tissues and cells including the hemocytes to levels many times those found in the environment.

Exposure to environmental pollutants could depress the phagocytic activity of the hemocytes and thereby increase susceptibility to disease. This study describes the use of a CL assay to determine the effects that chemicals often found in the environment have on the phagocytic activity of oyster hemocytes.

\section{MATERIALS AND METHODS}

Oysters. Crassostrea virginica collected from a clean area in the Chesapeake Bay (Hog Island) were maintained in a filtered, aerated aquarium filled with $60 \mathrm{gal}$ (225 l) of water containing 16 ppt salt (Instant Ocean, Aquarium Systems, Mentor, OH, USA). These 7 to 10 $\mathrm{cm}$ oysters were kept at 18 to $20^{\circ} \mathrm{C}$ and were allowed to acclimate for $1 \mathrm{wk}$ prior to use.

Isolation and preparation of hemocytes. A hole was drilled into each oyster at an angle to allow a needle to be inserted into the heart near the adductor muscle. Oysters were allowed to recover from the stress of drilling for $3 \mathrm{~d}$ prior to bleeding. Hemolymph was obtained from the pericardial sac using a 19 gauge needle.

The hemolymph from several (3 to 5) oysters was pooled to eliminate possible variation due to the response of individual oysters. Viable hemocytes were counted by trypan blue dye exclusion and numbers were adjusted using hemolymph filtered through a $0.22 \mu \mathrm{m}$ filter. The cells were dispensed into scintillation vials $\left(6 \times 10^{6}\right.$ per vial) and incubated at $20^{\circ} \mathrm{C}$ for $1 \mathrm{~h}$.

Chemiluminescence assay. Luminol was prepared in the manner described by Scott \& Klesius (1981) by dissolving $0.618 \mathrm{~g}$ boric acid, $0.78 \mathrm{~g}$ potassium hy- 
droxide and $0.14 \mathrm{~g}$ luminol in $10 \mathrm{ml}$ distilled water to prepare a stock solution. A working solution of luminol was prepared by diluting the stock solution 1:1000 in Hanks' balanced salt solution (HBSS). A stock solution of phorbol myristate acetate (PMA) was prepared by dissolving $1 \mathrm{mg}$ of PMA in $0.21 \mathrm{ml}$ of dimethyl sulfoxide (DMSO). Working solutions were made by diluting the PMA in Dulbecco's phosphate buffered saline (PBS). To replicate vials containing 2 $\mathrm{ml}$ hemocytes, $2 \mathrm{ml}$ of luminol was added. Finally, 2 $\mathrm{ml}$ of the PMA solution $\left(3 \mathrm{ng} \mathrm{ml} \mathrm{ml}^{-1}\right.$, final concentration) was added to initiate the $\mathrm{CL}$ response. Negative control vials were prepared by the addition of PBS in the place of the stimulus. Chemiluminescence was read in a Beckman scintillation counter in the out-of-coincidence mode as described by Stave et al. (1983). Data was entered into an IBM 4341 computer and mean values of duplicate vials were plotted. Significant differences between CL responses and treatment groups were determined using an analysis of variance procedure, $p<0.01$ (Sokal \& Rohlf 1973). All experiments were repeated at least once. Responses are presented in units of kilo-counts per minute (kcpm).

Chemicals. Solutions of aluminum chloride, cadmium chloride, copper chloride, and zinc chloride (1 $\mathrm{mg} \mathrm{ml}^{-1}$ ) were prepared in distilled water. Dieldrin and naphthalene (Sigma, St. Louis, MO, USA) were diluted in DMSO to a concentration of $5 \mathrm{mg} \mathrm{ml}$. Chlordane (Alltech, West Chester, PA, USA) was prepared in methanol at a concentration of $0.1 \mathrm{mg} \mathrm{ml}^{-1}$. All test dilutions were made in PBS.

In vitro studies. The effect of the chemicals in vitro was studied by their addition directly to incubation vials containing hemocytes. As some of the pollutants were dissolved in DMSO, controls were included to determine if DMSO had an effect on the CL response of the oyster hemocytes

In vivo studies. Oysters were drilled, allowed to acclimate and then placed in Pyrex jars containing $4 \mathrm{I}$ of sea salt water ( 6 oysters per treatment group). The pollutants were introduced directly into the water. At intervals of $24,48,72$ and $96 \mathrm{~h}$, oysters were bled, the hemolymph was pooled, hemocyte concentrations were adjusted to ca $6 \times 10^{6}$ cells $\mathrm{ml}^{-1}$ with filtered hemolymph, and the phagocytic activity was tested using the CL assay. No oysters contributing to the pool were bled more frequently than at $48 \mathrm{~h}$ intervals.

\section{RESULTS}

\section{Heavy metals}

Copper depressed the CL response of the oyster hemocytes both in vivo and in vitro. Low levels of copper $(0.4 \mathrm{ppm})$ did not decrease the CL response in vitro; however $4 \mathrm{ppm}$ decreased the response to a level approximately half that of the positive control. Exposure of the hemocytes to $40 \mathrm{ppm}$ copper totally eliminated the CL response (Fig. 1). In vivo studies yielded similar results. Oysters exposed to $40 \mathrm{ppm}$ copper died within 96 h of exposure. Oysters exposed to lower concentrations showed a greater number of dead hemocytes than the untreated control oysters, with the highest concentration of copper resulting in

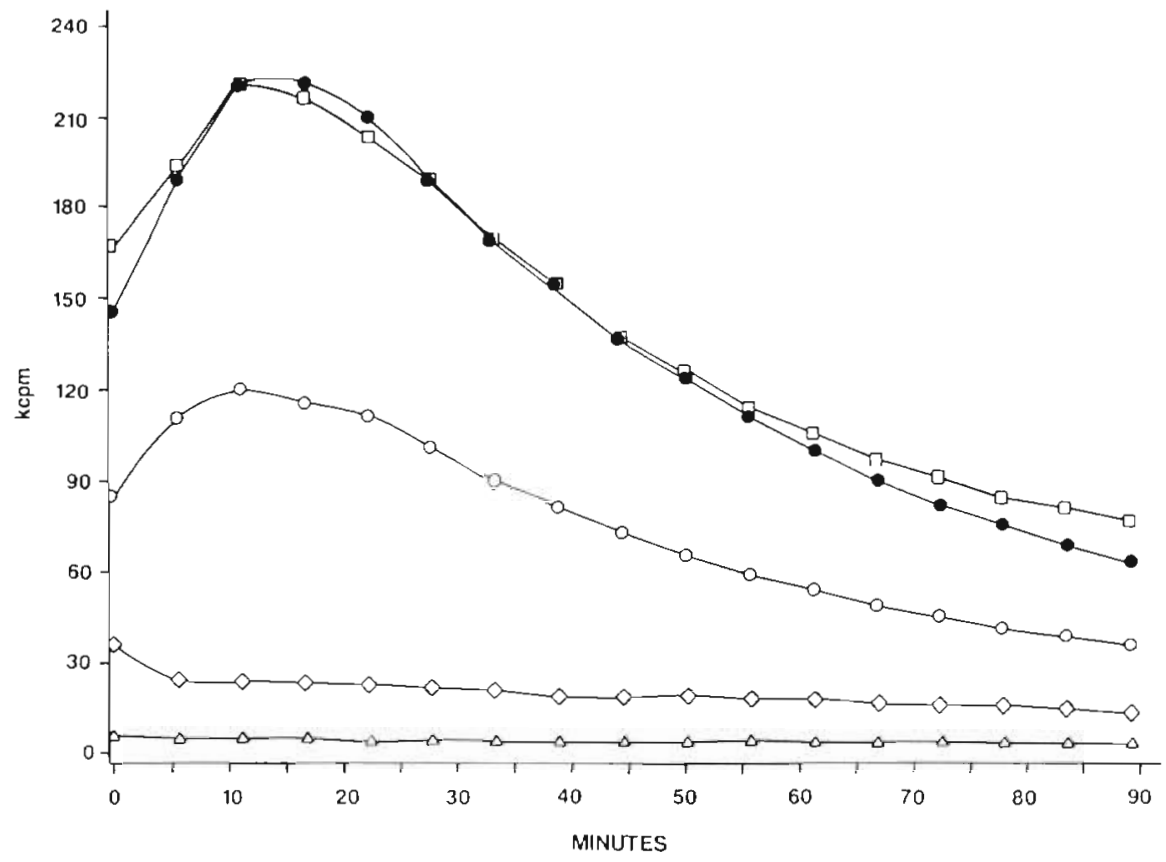

Fig. 1. Chemiluminescent response of oyster hemocytes exposed to copper in vitro for 1 h at $18^{\circ} \mathrm{C}$. Stimulus: $3 \mathrm{ng}$ $\mathrm{ml}^{-1}$ PMA. (O) 40 ppm copper; (0) 4

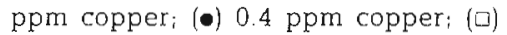
no copper; ( $/$ ) PBS control 


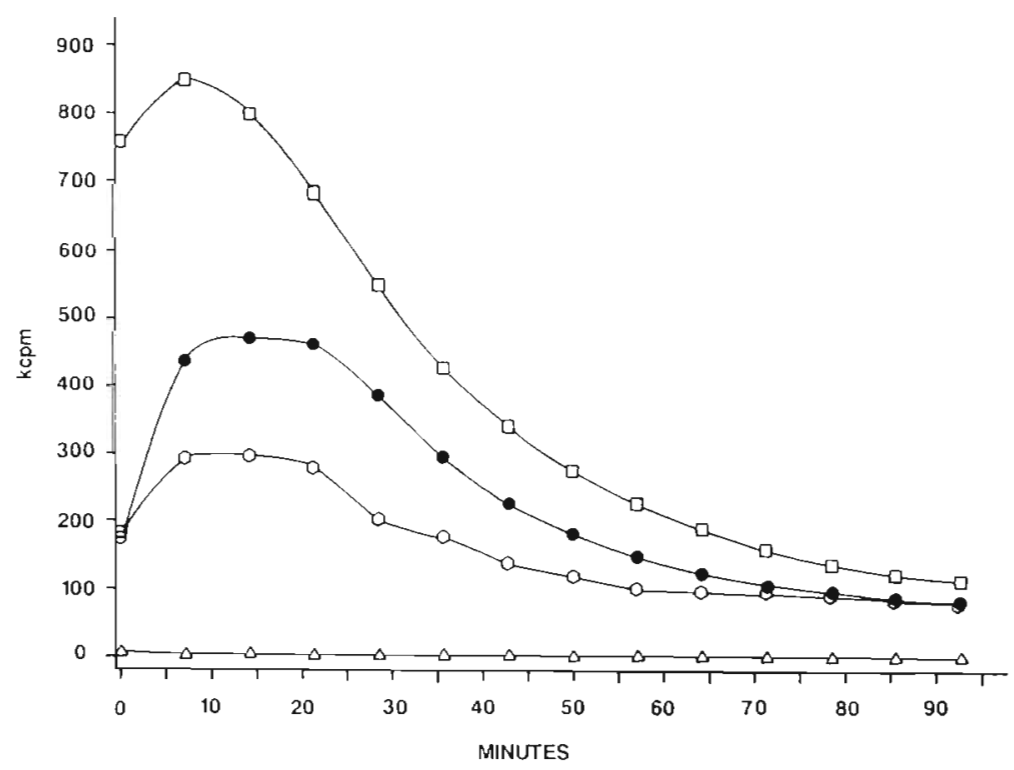

the highest number of dead cells observed. Oysters exposed to 0.4 and $4 \mathrm{ppm}$ copper for $24 \mathrm{~h}$ yielded hemocytes with a decreased CL activity (Fig. 2). The effect of copper on the CL response of the oyster hemocytes was greatest after $48 \mathrm{~h}$ exposure. After 72 and $96 \mathrm{~h}$ exposures, the hemocytes, though still exhibiting depressed CL, showed an increased percentage of the normal CL response, suggesting that the oysters were acclimating to the copper (Table 1).

Table 1. Crassostrea virginica. Chemiluminescent response of oyster hemocytes exposed to copper during a $96 \mathrm{~h}$ period

\begin{tabular}{|cc|}
\hline $\begin{array}{c}\text { Exposure time } \\
(\mathrm{h})\end{array}$ & $\begin{array}{c}\text { Response as a percent } \\
\text { of control }\end{array}$ \\
\hline 0 & 100 \\
24 & 63 \\
48 & 13 \\
72 & 32 \\
96 & 44 \\
a Oyster hemocytes were exposed in vivo at $23^{\circ} \mathrm{C}$ to \\
0.4 ppm copper for the indicated time \\
\hline
\end{tabular}

Exposure of hemocytes of aluminum slightly enhanced CL at a concentration of 40 to $80 \mathrm{ppm}$ while no change from the control response was observed upon exposure to $160 \mathrm{ppm}$. A significant decrease in the response was noted upon exposure to $320 \mathrm{ppm}$ aluminum in comparison to the unexposed controls (Fig. 3). Similarly, cadmium and zinc also enhanced the CL response of the hemocytes over that seen with the unexposed controls at concentrations below 160 ppm, whereas exposure in vitro to $320 \mathrm{ppm}$ of cadmium or zinc decreased the CL response (data not shown).
Fig, 2. Chemiluminescent response of hemocytes isolated from cysters exposed to copper for $24 \mathrm{~h}$ at $23^{\circ} \mathrm{C}$. Stimulus: $3 \mathrm{ng} \mathrm{m}{ }^{-1}$ PMA. (O) 4 ppm copper; $(\bullet) 0.4$ ppm copper; (ㄷ) no copper; $(\triangle)$ PBS control

\section{Pesticides}

The DMSO concentrations used in preparation of the pesticides had no effect on the CL response. In vitro, dieldrin did not alter the CL response of the oyster hemocytes at $0.1 \mathrm{ppm}$; however, incubation with $1 \mathrm{ppm}$ dieldrin decreased the CL response, and incubation with 10 ppm resulted in an even greater decrease (Fig. 4). In vivo exposure to 0.1 and $1 \mathrm{ppm}$ dieldrin for $24 \mathrm{~h}$ resulted in a significant increase in the CL response of the exposed hemocytes over the unexposed controls (Fig. 5). However, after $48 \mathrm{~h}$, this enhancement had lessened and after $96 \mathrm{~h}$ of exposure the hemocytes exhibited a CL response that was slightly depressed in comparison with that of the control hemocytes. Chlordane, another pesticide, resulted in a dose-dependent decrease in the CL of the exposed hemocytes; however, a concentration of $100 \mathrm{ppm}$ was required to cause significant depression in the CL response of the hemocytes in vitro (data not shown).

\section{Organic compounds}

Exposure to 2 organic compounds, 2,4-dinitrophenol and naphthalene, depressed CL of oyster hemocytes at high concentrations in vitro. Exposure to both compounds at 0.1 and $1 \mathrm{ppm}$ did not significantly alter the CL response of the hemocytes in comparison with the unexposed control. Exposure to $10 \mathrm{ppm}$ slightly decreased the CL response and a greater decrease was seen upon exposure to $100 \mathrm{ppm}$, as shown in Fig. 6 for naphthalene. In vivo exposure of oysters for $24 \mathrm{~h}$ to $1 \mathrm{ppm}$ naphthalene resulted in hemocytes that exhibited an enhanced CL response over the control hemocytes. There was no significant difference 

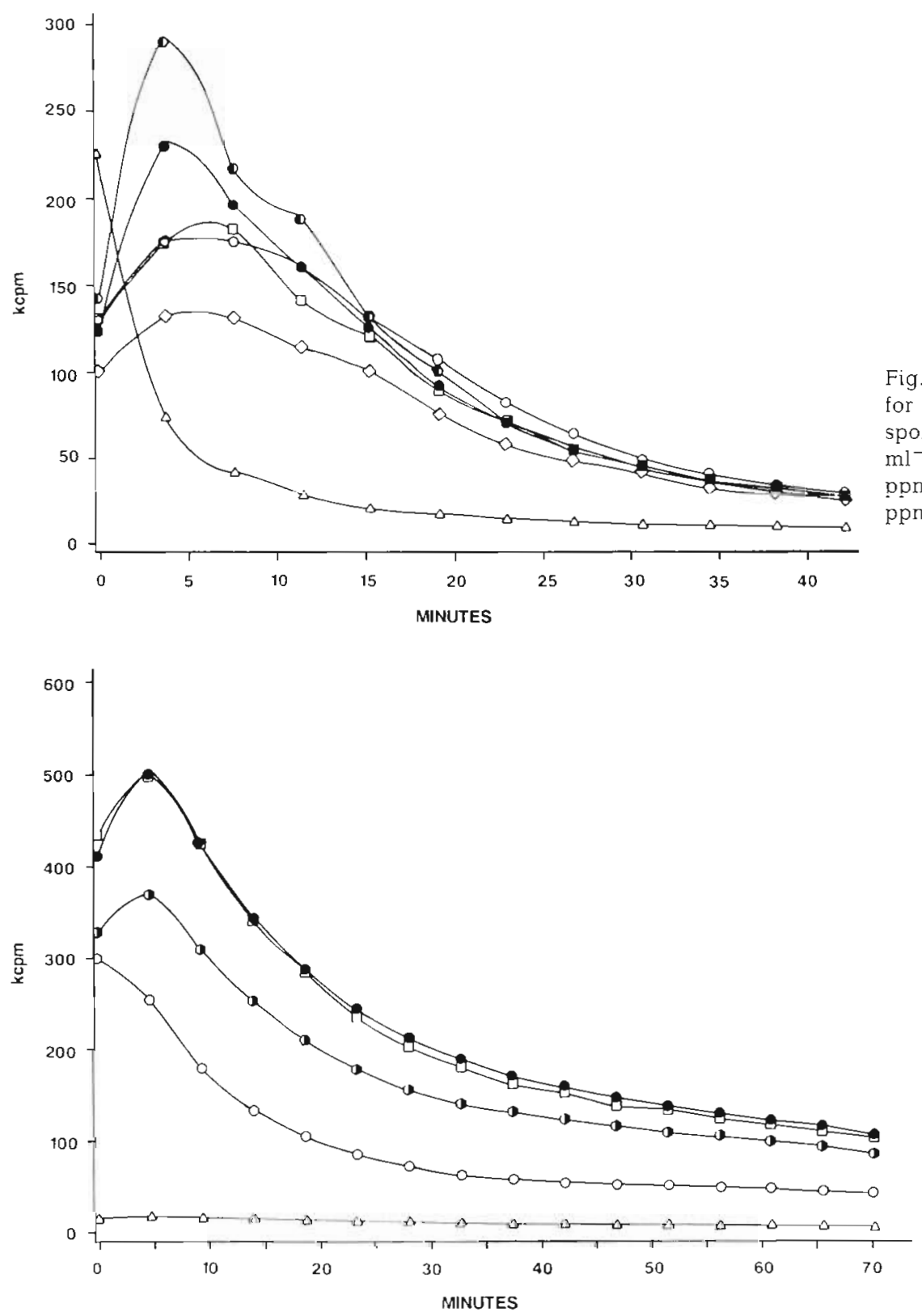

Fig. 3. Effect of exposure to aluminum in vitro for $1 \mathrm{~h}$ at $18^{\circ} \mathrm{C}$ on the chemiluminescent response of oyster hemocytes. Stimulus: $3 \mathrm{ng}$ $\mathrm{ml}^{-1}$ PMA. $(\diamond) 320$ ppm aluminum; (0) 160 ppm aluminum; (•) 80 ppm aluminumi (1) 40 ppm aluminum; ( $\square$ ) no aluminum; (A) PBS control between hemocytes isolated from oyster exposed to 10 ppm naphthalene and those from unexposed oysters at $24 \mathrm{~h}$. After $72 \mathrm{~h}$, the hemocytes exposed to 1 ppm naphthalene were still enhanced over the response of the control oysters; however, oysters exposed to 10 ppm naphthalene showed a significantly decreased CL response (Fig. 7).

\section{DISCUSSION}

Of the pollutants tested in this study, copper appears to be the most toxic to the cells both in vivo and in vitro. This is indicated by the fact that the
Fig. 4. Effect of dieldrin in vitro on the chemiluminescent response of oyster hemocytes after 1 h at $18^{\circ} \mathrm{C}$. Stimulus: 3 $\mathrm{ng} \mathrm{ml^{-1 }}$ PMA. (O) 10 ppm dieldrin; ( 1 ppm dieldrin; $(\bullet) 0.1 \mathrm{ppm}$ dieldrin; $(\square)$ no dieldrin; (A) PBS control levels of copper that depress chemiluminescence are much lower than the levels needed of the other pollutants. Copper concentrations in polluted waters have been measured as high as $0.1 \mathrm{ppm}$. As the oysters may accumulate the copper at 1000 times the environmental level (Pesch et al, 1979) the actual exposure may be as high as $100 \mathrm{ppm}$, a level that will depress phagocytic ability of the hemocytes. The effect of the copper may be due to killing hemocytes as well as damage to the cells while still alive. However, cell killing cannot account for the decrease in the response as the viable cell concentrations of in vivo treatment groups were adjusted just before assay so that they were equal. 


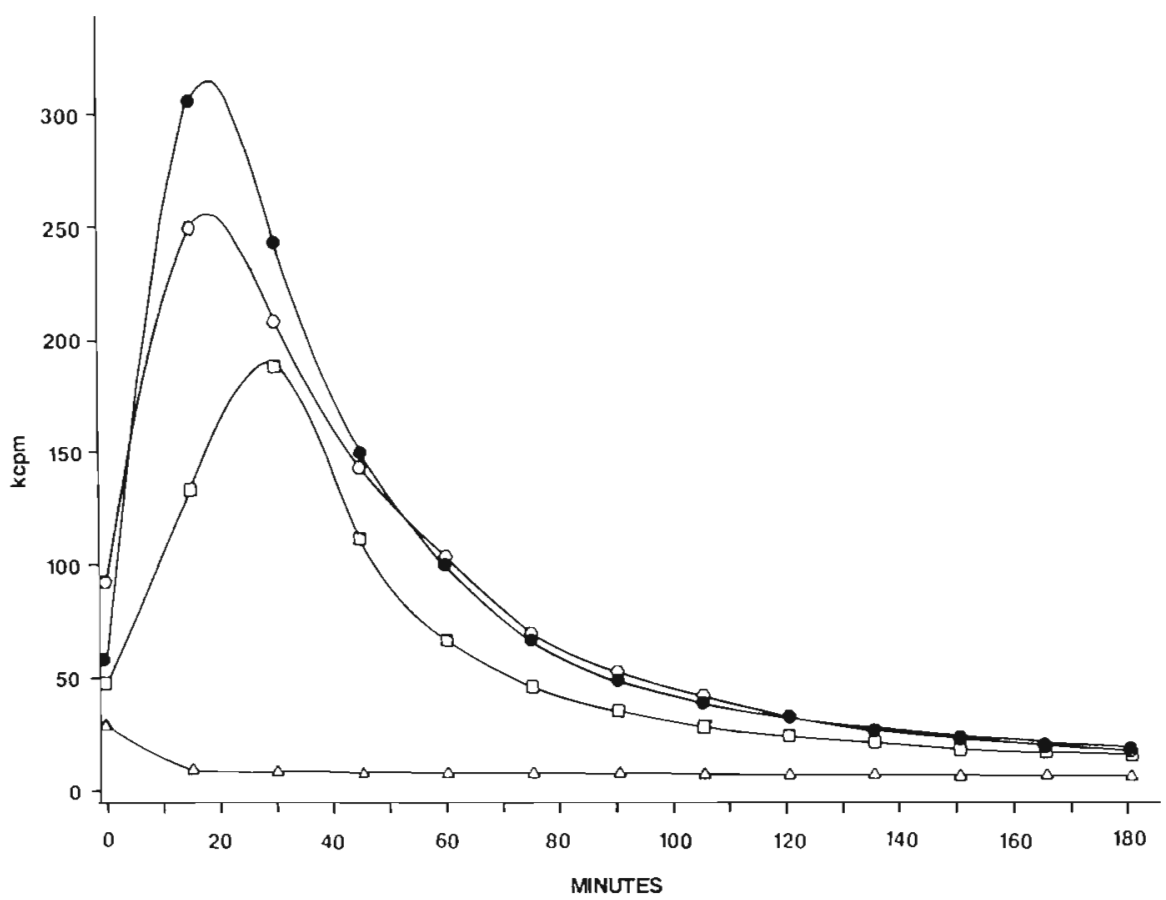

Fig. 5. Chemiluminescent response of hemocytes isolated from oysters exposed to dieldrin for $24 \mathrm{~h}$ at $23^{\circ} \mathrm{C}$. Stimulus: 3 $\mathrm{ng} \mathrm{m}{ }^{-1}$ PMA. (O) $1 \mathrm{ppm}$ dieldrin; (•) 0.1 ppm dieldrin; ( $\square$ ) no dieldrin; ( $\triangle$ ) PBS controls

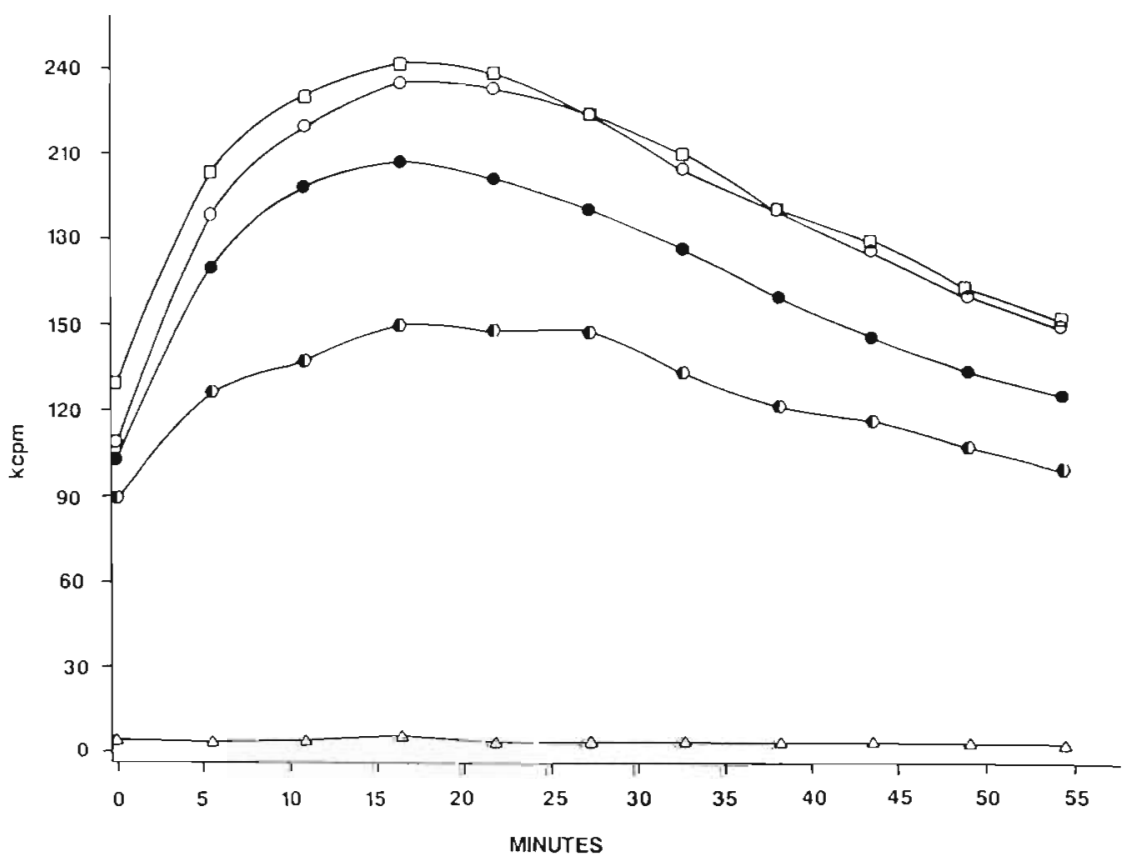

Fig. 6. Effest of naphthalene in vitro on the chemiluminescent response of oyster hemocytes after $1 \mathrm{~h}$ at $18^{\circ} \mathrm{C}$. Stimulus: 3 mg $\mathrm{ml}^{-1} \mathrm{PMA}$. (1) 100 ppm naphthalene; (•) $10 \mathrm{ppm}$ naphthalene; (O) $1 \mathrm{ppm}$ naphthalene; ( $\square$ ) no naphthalene; $(\triangle)$ PBS control

Evidence of acclimation is seen in oysters that are exposed to copper in vivo. The oyster hemocytes were reduced to their lowest response after $48 \mathrm{~h}$ exposure and then began to make a recovery during the time period studied $(96 \mathrm{~h}$ ).

Levels of dieldrin have been reported up to $0.1 \mathrm{ppm}$ in polluted waters. As the oysters have been found to accumulate dieldrin at a level of up to 5000 times the environmental level (Emanuelson 1978), the levels of dieldrin the oyster hemocytes would actually be exposed to would be in the range 0.1 to $500 \mathrm{ppm}$. The levels of dieldrin used in this study fall within this range and were found to depress the phagocyte activity at levels as low as $10 \mathrm{ppm}$, well below the potential upper limit of exposure.

In vivo exposure to low levels of naphthalene and dieldrin initially stimulate and increase the $\mathrm{CL}$ response of hemocytes isolated from exposed oysters. This may be an initial reaction on the part of the hemocytes in response to a stressful agent. It has been 


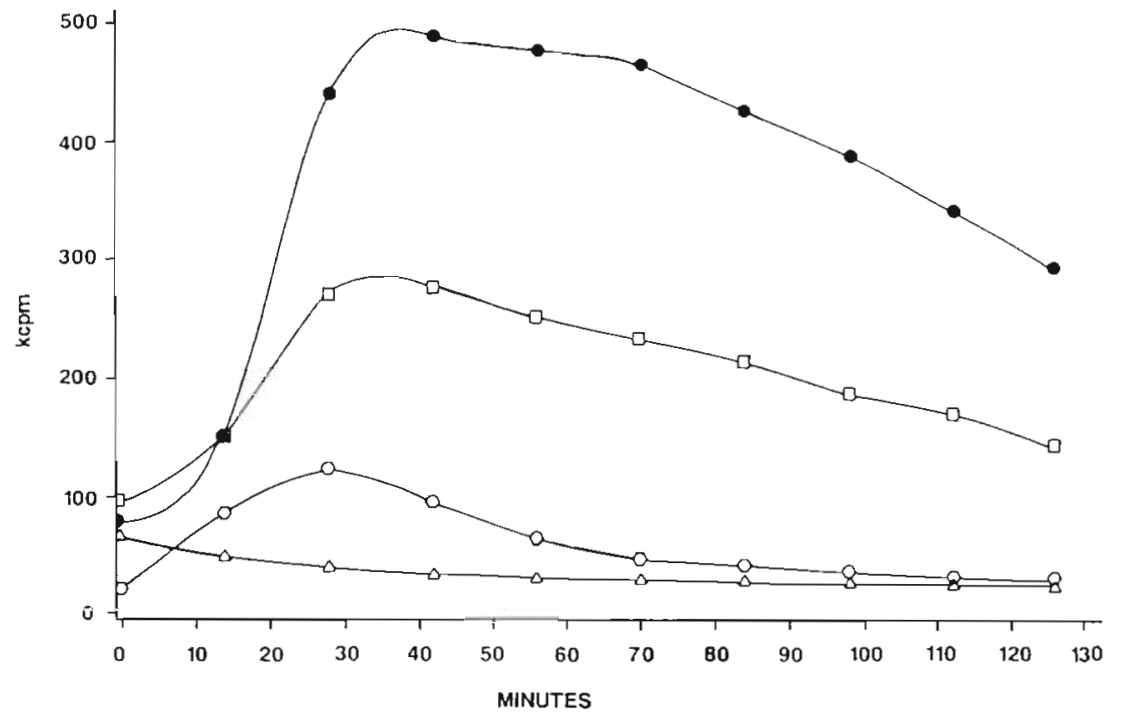

Fig. 7. Chemiluminescent response of hemocytes isolated from costers exposed to naphthalene for $72 \mathrm{~h}$ at $23^{\circ} \mathrm{C}$ Stimulus: $3 \mathrm{ng} \mathrm{m} \mathrm{m}^{-1}$ PMA. (O) $10 \mathrm{ppm}$ naphthalene; (•) 1 ppm naphthalene; $(0)$ no naphthalene; $(\triangle)$ PBS control observed that exposure to sublethal levels of pollutants may also enhance the phagocytic response of rainbow trout phagocytes (Elsasser et al. 1986). Although an initial increase is observed, the final effect over time is a decrease in the CL response of the exposed hemocytes. This may be due, in part, to the accumulation of the pollutant in the oyster tissues.

As seen in this study, exposure to pollutants can decrease the phagocytic ability of oyster hemocytes as measured by $\mathrm{CL}$ response. The sensitivity and rapidity of the CL assay, as well as the ease and practicality of the in vitro test are attractive features. Studies are currently in progress to determine if any correlation exists between depression of the CL response and increased susceptibility to infection. If there is a correlation, then the CL assay may prove to be a useful predictor of those pollutants that are harmful to finfish and shellfish.

Acknowledgements. This work was supported by Grant R811278-01-0 from the US Environmental Protection Agency.

\section{LITERATURE CITED}

Allen, R. C., Sternholm, R. L., Steele, R. H. (1972). Evidence for generation of an electronic excitation state(s) in human polymorphonuclear leucocytes and its participation in bactericidal activity. Biochem. biophys. Res. Commun. 47: $679-684$

Brummer, E., Sugar, A. M., Stevens, D. A. (1985). Enhanced oxidative burst in immunologically activated but not eli- cited polymorphonuclear leukocytes correlates with fungicidal activity. Infection Immunity 49: 396-401

Cheng, T. C. (1975). Functional morphology and biochemistry of molluscan phagocytes. Ann. N. Y. Acad. Sci. 266: 343-379

Ellis, A. E., Munro, A. L. S., Roberts, R. J. (1976). Defense mechanisms in fish. I. A study of the phagocytic system and the fate of intraperitoneally injected particulate material in the plaice. J. Fish Biol. 8: 67-78

Elsasser, M. S., Roberson, B. S., Hetrick, F. M. (1986), Effects of metals on the chemiluminescent response of rainbow trout (Salmo gairdneri) phagocytes. Vet. Immunol. Immunopath. 12: 243-250

Emanuelson, M., Lincer, J. C., Rifkin, E. (1978). The residue uptake and histology of the American Oyster (Crassostrea virginica Gmelin) exposed to dieldrin. Bull environ. Contam. Toxic. 19: 121-129

Mason, J. W. Rowe, D. R. (1976). The accumulation and loss of dieldrin and endrin in the Eastern oyster. Arch. environ. Contam. Toxic. 4: 349-360

Pesch, G., Stewart, N., Pesch, C. (1979). Copper toxicity to the bay Scallop (Argopecten irradians). Bull. environ. Contam. Toxic. 23: 759-765

Scott, A. L., Klesius, P. H. (1981). Chemiluminescence: a novel analysis of phagocytosis in fish. Dev. biol Stand. 49 243-254

Sokal, R. R., Rohlf, F. J. (1973). Introduction to biostatistics. W. H. Freeman and Co., San Francisco, p. 161-184

Stave, J. W., Roberson, B. S., Hetrick, F. M. (1983). Chemiluminescence of phygocytic cells isolated from the pronephros of striped bass. Devl. comp. Immun., N. Y. 7: 268-276

Zamuda, C. D., Wright, D. A., Smucker, R. A. (1983). The importance of dissolved organic compounds in the accumulation of copper in the American oyster Crassostrea virginica. Mar. envirl Res. 16: 1-12

Zaroogian, G. E. (1980). Crassostrea virginica as an indicator of cadmium pollution. Mar. Biol. 58: 275-284 